\title{
ФИЛОСОФИЯ
}

DOI: https://doi.org/10.15688/lp.jvolsu.2017.3.1

UDC 14

LBC 87.3

\section{N.O. LOSSKY DOCTRINE AS A SYNTHESIS OF RUSSIAN AND EUROPEAN TRADITIONS OF THOUGHT ${ }^{1}$}

\author{
Elena V. Serdyukova \\ Southern Federal University, Rostov-on-Don, Russian Federation
}

\begin{abstract}
Russian religious philosopher N.O. Lossky based on the studying new archival materials. N.O. Lossky was one of the outstanding representatives of the Russian Diaspora, shared the fate of the Russian creative intelligentsia, forcibly expelled from Russia in 1922. The idea of "everything is immanent to everything" became a leading theme in the work of the Russian philosopher and brought to the construction of intuitionism in epistemology and to the theory of ideal-realism and hierarchical personalism in the ontology which represent his theoretical philosophy. The formation of the epistemological and ontological views of Lossky occurred mainly under the influence of Western philosophical tradition: Plotinus, Kant, Leibniz, Bergson and other thinkers, although only the book by P. Florensky "the Pillar and ground of the truth" gave impetus to the finalization of the metaphysics of N.O. Lossky. From about 1930 Lossky goes on to create a practical philosophy and at the same time he starts his acquaintance with Russian philosophy. Lossky himself repeatedly in his work refers to the legacy of A.S. Khomyakov, Vl. Solovyev, F.M. Dostoevsky, N.A. Berdyaev, L.P. Karsavin and other Russian thinkers. Investigation of new sources allows to have a fresh look at the role and place of N.O. Lossky in Russian philosophy and significantly expands the traditional notion of the philosopher as the Creator of the theory of intuitionism and ideal-realism. The practical philosophy of N.O. Lossky is of great interest, Russian thinker worked in exile over it until his death. Lossky tried to create a universal philosophical system that would reconcile empiricals and rationalists, nominalists and realists, synthesizes all the best practices of both Western and Russian traditions of thought.
\end{abstract}

Key words: spiritual legacy, emigration, Europe, Russia, Russian philosophy, intuitionism, ideal-realism.

УДК 14

ББК 87.3

\section{УЧЕНИЕ Н.О. ЛОССКОГО КАК СИНТЕЗ РУССКОЙ И ЕВРОПЕЙСКОЙ ТРАДИЦИЙ МЫСЛИ ${ }^{1}$}

\section{Елена Владимировна Сердюкова}

Южный федеральный университет, г. Ростов-на-Дону, Российская Федерация

Аннотация. В статье предпринимается попытка провести реконструкцию наследия известного русского религиозного философа Н.О. Лосского на основе исследования новых архивных материалов. Н.О. Лосский был одним из выдающихся представителей русского зарубежья, разделившим судьбу русской творческой интеллигенции, насильственно высланной из России в 1922 году. Идея «все имманентно всему» стала ведущим мотивом в творчестве русского философа и привела в гносеологии к построению интуитивизма и в онтологии к созданию теории идеал-реализма и иерархического персонализма, которые представляют его теоретическую философию. Формирование гносеологических и онтологических взглядов 
Лосского происходило преимущественно под влиянием западноевропейской философской традиции Плотина, Канта, Лейбница, Бергсона и других мыслителей, хотя только книга П. Флоренского «Столп и утверждение истины» дала толчок к окончательному оформлению метафизики Н.О. Лосского. Примерно с 1930 г. Лосский переходит к созданию практической философии, и в это же время начинается его знакомство с русской философией. Сам Лосский неоднократно в своем творчестве обращается к наследию А.С. Хомякова, Вл. Соловьева, Ф.М. Достоевского, Н.А. Бердяева, Л.П. Карсавина и других русских мыслителей. Исследование новых источников позволяет по-новому взглянуть на роль и место Н.О. Лосского в русской философии и существенно расширяет традиционное представление о философе не только как о создателе теории интуитивизма и идеал-реализма. Весьма большой интерес представляет практическая философия Н.О. Лосского, над созданием которой русский мыслитель работал в эмиграции до самой смерти. Лосский пытался создать такую универсальную философскую систему, которая примирит эмпириков и рационалистов, номиналистов и реалистов, синтезирует все то лучшее, что было наработано как западной, так и русской традициями мысли.

Ключевые слова: духовное наследие, эмиграция, Европа, Россия, русская философия, интуитивизм, идеал-реализм.

Русское зарубежье представляет собой уникальный феномен в истории России. Октябрьская социалистическая революция 1917 г., шок творческой интеллигенции на происходящие в стране события, неприятие советской власти и высылка из страны - все это послужило спусковым механизмом для формирования в эмиграции огромного пласта русской культуры. В то время как советская власть предпринимала попытки «стереть» значительную часть культурно-исторической памяти русского народа, вытравить из русской души веру в Бога и усиленными темпами строила новое государство с новой идеологией, русское зарубежье стало своего рода охранителем великой русской культуры и традиций русского народа. После высылки из страны значительной части русской интеллигенции в единой связке «территория наследие - идентичность - память», столь важной для существования и процветания нации, произошли кардинальные изменения. Осталась территория, правда перекроенная границами нового государства - СССР. Возникла проблема построения новой идентичности - советской. Определенные «фрагменты» культурно-исторической памяти были стерты или интерпретированы так, чтобы они гармонично вписывались в идею исторической неизбежности крушения царского режима и победы марксизмаленинизма в России. Что же касается культурного наследия, то нить преемственности в самой России была прервана. Произошел трагический и противоестественный разрыв, деление на две последующих па- раллельных во времени линии развития: советской культуры, ареал распространения и развития которой определялся границами Советского государства, и культуры русского зарубежья, насильно оторванной от материнского лона, но сохранившей и приумножившей многие традиции великой русской культуры. В начале 90-х гг. ХХ в. перед российской общественностью возникла задача возвращения духовного наследия русской эмиграции на родину. Одним из выдающихся представителей русского зарубежья был русский религиозный философ Н.О. Лосский, разделивший судьбу русской творческой интеллигенции, насильственно высланной из России в 1922 г., «патриарх русской философии», как назвал его С.А. Левицкий [2, с. 186].

Весь период творчества Н.О. Лосского можно условно разделить на два этапа: до 1930 г., когда Лосский создает свою теоретическую философию (построение интуитивизма и идеал-реализма), и после 1930 г., когда он приступает к разработке практической философии (куда входят философия ценностей, этика, эстетика и т. п.). В историю отечественной мысли Н.О. Лосский вошел как крупнейший гносеолог и создатель последовательной философской системы, изложенной в работах: «Обоснование интуитивизма», «Мир как органическое целое», «Логика», «Свобода воли», «Чувственная, интеллектуальная и мистическая интуиция», «Типы мировоззрений», «Бог и мировое зло. Основы теодицеи», «Ценность и бытие», «Условия абсолютного добра», «Достоевский и его христианское ми- 
ропонимание», «Характер русского народа», «История русской философии» и др.

Свой творческий путь Н.О. Лосский начинал в стенах Санкт-Петербургского университета. Будучи студентом физико-математического факультета, Лосский интересуется ботаникой и анатомией, но после знакомства с философом-лейбницианцем А.А. Козловым выбирает философию как главное направление своей деятельности и поступает на историко-филологический факультет. Рождение собственного мировоззрения происходит в 1898 году. В неопубликованном очерке «Влияния, которым я подвергался» Лосский следующим образом описывает эволюцию своих философских взглядов: «Основная идея интуитивизма "все имманентно всему" пришла мне в голову при виде улицы, утопавшей в тумане. В это время (1898 г.) я под влиянием лейбницианца А.А. Козлова, у которого жил, был твердо убежден, что мое “я” есть субстанция (монада Лейбница), а под влиянием университетского учителя моего кантианца А.И. Введенского, талантливого педагога, был абсолютно убежден в правоте Канта, утверждающего, что знание возможно только о том, что имманентно сознанию. Первое влияние (Лейбница - Козлова) влекло меня в область метафизики, второе влияние (Канта Введенского) запрещало мне занятия метафизикою, как гносеологически неоправданные. Идея "все имманентно всему”, основной замысел интуитивизма давал мне возможность разрабатывать метафизику, гносеологически оправдав ее и сохранив тезис Канта "только имманентное сознанию познаваемо". Но имманентным сознанию оказался в моем замысле весь мир вещей в себе, и моя гносеология оказалась близкою к "Критике чистого разума”, однако придающая тезису Канта обратный смысл: не условия знания суть условия вещей, а условия вещей суть условия знания (см. Гносеологическое введение в мою “Логику”). Когда с 1898 г. я начал разрабатывать мысленно интуитивизм, я стал замечать и подхватывать идеи тех философов прежних веков, которые высказывали сходные учения» [6, с. 1-2].

Идея всепроникающего мирового единства стала для Н.О. Лосского руководящей мыслью и привела в гносеологии к интуити- визму, в метафизике - к органическому мировоззрению, построению идеал-реализма. Интуитивизм имел основой убеждение русского философа в непосредственном созерцании бытия в подлиннике. Лосский разрабатывает свое учение в контексте западноевропейской философской традиции, которая оказала на него огромное влияние (прежде всего идеи Лейбница и Канта). Русский философ находит точки соприкосновения своих гносеологических построений с идеями Шеллинга, Спенсера, Липпса, Бергсона, Шуппе и других мыслителей.

Коренным образом отличается учение Н.О. Лосского об интуиции от учения об интуиции Бергсона. Современник Лосского Г. Ловцкий в рецензии на книгу «Обоснование интуитивизма» пишет: «...универсалистский эмпиризм или мистический интуитивизм проф. Лосского совсем другого порядка. Вечная наличность абсолютного нормального сознания для него не подлежит сомнению. Не из интимной бергсоновской мелодии “моего я" он исходит при построении своей теории знания, а из сверхиндивидуального сознания, усилием тройной интуиции проникающего в мир сущности. Чувственной интуицией, высшее осуществление которой проф. Лосский видит в прочувствовании художником мира, мы воспринимаем конкретную действительность во всем богатстве ее проявлений; интеллектуальной, умозрительной интуицией мы путем сравнения различных проявлений бытия устанавливаем объективную истину о подлинном бытии и получаем научное познание мира; и, наконец, в сверхчувственном опыте мы познаем сверхмировое начало, Абсолют» [3, с. 387]. В своем учении Н.О. Лосский пытается примирить эмпиризм и рационализм, выработать универсальную теорию познания. Как отмечает уже упомянутый выше Ловцкий, «проф. Лосский берет все положительное от эмпиризма, рационализма и мистицизма, не впадая в их преувеличения, и получает стройную теорию познания мира, объединенного сверхиндивидуальным мировым разумом, координирующим друг другу все стороны мировой жизни» [3, с. 388].

Разработав интуитивизм, Н.О. Лосский приступает к построению метафизической системы. В своей книге «Воспоминания» в гла- 
ве, посвященной переходу от теории знания к метафизике, Н.О. Лосский определенно заявляет о своей принадлежности к сторонникам определенной метафизической системы - лейбницианского персонализма и пишет о Лейбнице как о своем любимом философе [7, c. 172-173]. Русскому философу необходимо было переработать персонализм Лейбница в связи с интуитивизмом - «нужно было выяснить интимную связь всех частей мира друг с другом, связь, благодаря которой познающее существо может нескромно заглядывать прямо в недра чужого бытия» [7, с. 172]. С другой стороны, ему предстояло решить вопрос об отношении между общим и индивидуальным, в его сознании номинализм столкнулся со средневековым реализмом.

В поисках синтеза персоналистического индивидуализма с идеалистическим универсализмом Н.О. Лосский обращается к помощи прошлого философии (прежде всего, конечно, к немецкой классической философии), читает произведения Фихте, Шеллинга и Гегеля. Познакомившись с учением Гегеля, Лосский отмечает, что определенного влияния на него немецкий философ не произвел [6], хотя «Логику» Гегеля считает принадлежащей к числу «величайших творений философской мысли» [7, с. 174]. Русский философ обращает внимание на Плотина, прочитывает все философские произведения Лейбница и все его письма. И признается, что «с русской философиею я, к стыду своему, как и большинство русских людей, почти вовсе не был знаком» (за исключением работ А. Козлова, труда Л. Лопатина «Положительные задачи философии» и некоторых работ Вл. Соловьева) $[7$, c. 174].

«Уже в "Обосновании интуитивизма" было намечено учение о мире как органическом целом, и следовательно, поставлена задача найти онтологическую спайку между элементами мира. В теории знания эта спайка была установлена лишь как координация познающего субъекта со всеми существами и процессами всего мира. Теперь предстояло найти условия существования самой этой координации» [7, с. 176]. Несмотря на приверженность западной философской традиции и поиск в ней опоры для построения своей системы, толчок для завершения учения об орга- нической связи деятелей друг с другом, построения метафизики дает труд русского философа П. Флоренского «Столп и утверждение Истины», вышедший в 1913 году. «Большая заслуга Флоренского заключается в том, что он сознательно ввел понятие единосущия в онтологию мирового бытия; установив это подобие между строением мира и Св. Троицы, он сильно подвинул вперед разработку христианского миропонимания. Я подхватил мысль Флоренского о единосущии тварных личностей и, задумавшись над вопросом о различии между единосущием Лиц Св. Троицы и единосущием тварных существ, пришел к различению понятий конкретного и отвлеченного единосущия. Тварные существа я понял, как спаянные друг с другом онтологически воедино тожественными формальными принципами деятельности их, принципами строения времени, пространства и т. п. Совокупность этих принципов, обусловливающих формальную разумность строения мира, я назвал Отвлеченным Логосом» [7, с. 176-177]. Итоги метафизических исканий воплотились в книге «Мир как органическое целое». Таким образом, если говорить о первом этапе творческого пути русского мыслителя, разработке теоретической философии, то очевидно преимущественное влияние на нее западноевропейской философской традиции. Именно этим объясняется тот факт, что, например, А.Ф. Лосев в статье «Русская философия» (1918 г.) относит Н.О. Лосского не к самобытной русской философии, а к заимствованной на Западе и переработанной на западный лад русской философии, которую Лосев считал бесплодной, так как она практически не выходит за рамки теории познания [4, с. 235]. Хотя, еще раз хотелось бы подчеркнуть, только книга Павла Флоренского «Столп и утверждение истины», а именно учение Флоренского о единосущии тварных личностей, помогла Лосскому «достроить» его метафизику.

Уже в эмиграции, в 1923 г., русскому философу заказывают статью о Вл. Соловьеве и его последователях для журнала «Slavonic Review». Погружаясь в изучение взглядов Соловьева, Н.О. Лосский с удивлением осознает свою идейную близость его учению. В свое время знакомство с Соловьевым произвело на него сильное впечатление. Вспоми- 
ная свою встречу с ним в 1900 г., Н.О. Лосский отмечает, что Владимир Соловьев «с интересом и симпатиею слушал мои рассуждения о гносеологической проблеме, а я, увлекаясь в то время логикою и гносеологиею, вовсе и не подозревал, что через двадцать лет окажусь в разработке метафизической системы наиболее близким к Соловьеву из всех русских философов» [7, с. 90]. В архиве Н.О. Лосского хранится документ, датированный 1935 г., который, по всей вероятности, представляет собой ответы на вопросы, уточняющие некоторые факты жизненного пути Н.О. Лосского и его творческой биографии. Один из пунктов (вероятнее всего, это был вопрос о влиянии на Лосского русских мыслителей) содержит следующую информацию: «Очень высоко ценю Достоевского, как художника и мыслителя; также высоко ценю Толстого, как художника, а "философские" произведения Толстого считаю стоящими далеко ниже среднего уровня. Вл. Соловьева ценю высоко как философа и поэта» [5]. В этой же рукописи Н.О. Лосский признается, что в данный момент работает над своей этикой и хочет написать «Теодицею» и «Ценность христианства». Н.О. Лосскому удалось осуществить задуманное несколько позже, в 40-е годы из под его пера в свет выходят «Бог и мировое зло. Основы теодицеи» и «Условия абсолютного добра (основы этики)». Что касается книги о ценности христианства, она вышла только в 1953 г. под названием «Достоевский и его христианское миропонимание». Как признается Н.О. Лосский, когда-то Н.В. Тесленко дал ему совет написать книгу о ценности христианства наподобие книги Шатобриана «Le génie du Christianisme». Понимая, что достаточными знаниями о христианстве в целом он не обладает, Лосский решает использовать «одну из разновидностей христианства, именно понимание его таким гением, как Достоевский» [7, с. 227]. В конце 40 -х и начале 50 -х гг. Лосский работает над книгой «История русской философии», в которой находит созвучия своему интуитивизму и идеал-реализму во взглядах А.С. Хомякова, И.В. Киреевского, Вл. Соловьева, С. Франка и многих других русских философов. Таким образом, можно сказать, что Лосский пытается создать такую универсальную философскую систему, которая примирит эмпириков и рационалистов, номиналистов и реалистов, синтезирует все то лучшее, что было наработано как западной, так и русской философскими традициями.

Вся преподавательская и научная жизнь Н.О. Лосского была неразрывно связана с университетами России, Европы и США. Прежде всего речь идет о Санкт-Петербургском университете (до отъезда из России в 1922 г.), в котором Лосский прошел путь от студента (обучение на физико-математическом, а затем историко-филологическом факультетах) до приват-доцента, а затем и профессора кафедры философии (с 1916 г.). После высылки из России вся дальнейшая жизнь русского мыслителя связана с такими духовными центрами русской эмиграции, как Прага, Братислава, Париж. Последним местом педагогической и научной деятельности Лосского в качестве профессора становится Свято-Владимирская духовная академия в Нью-Йорке.

Двадцать лет жизни философа (19221942) связаны с Прагой и преподаванием в чешских учебных заведениях. Как отмечает ученик Лосского С.А. Левицкий, чешские научные круги недооценили Лосского как ученого и преподавателя, один из профессоров Карлова университета Козак дает отрицательный отзыв на работу «Свобода воли», не рекомендуя к печати в одном из чешских издательств. Н.О. Лосский получает кафедру по истории русской философии в Карловом университете только в 1937 году. В 1942 г. Лосский с семьей переезжает в Братиславу. В 1942-1945 гг., когда Лосский был приглашен Братиславским университетом, у него вскоре образуется круг его словацких поклонников, среди которых самым выдающимся был профессор Йозеф Диешка.

Следующий период жизни Лосского связан с Парижем (1945-1946 гг.) и преподавательской деятельностью в Свято-Сергиевском православном богословском институте. В конце 1946 г. Лосский переезжает в США к младшему сыну Андрею, с 1947 г. преподает в Свято-Владимирской духовной академии в Нью-Йорке. Но особую роль в его судьбе играет именно Париж, где остаются жить двое сыновей Н.О. Лосского - Владимир и Борис Лосские со своими семьями и где Н.О. Лосский проводит последние годы своей жизни. 
Архив Н.О. Лосского, сохранившийся в Париже, это пример интеллектуальных связей между Россией и Францией в период вынужденной эмиграции значительной части русской интеллигенции.

Творчество философа в различных его аспектах (особенно интуитивизм, идеал-реализм, персонализм) не раз становилось предметом исследования российских ученых (работы П.П. Гайденко, Н.В. Мотрошиловой, М.А. Маслина, В.П. Филатова, А.А. Гусейнова, А.А. Ермичева, С.М. Половинкина, О.Т. Ермишина и др.). Его заслуги относят «к области метафизики» (В. Зеньковский), «гносеологии, логики, метафизики и философии ценностей» (С.А. Левицкий). Внимание многих исследователей в большей степени приковано к той части учения русского философа, которую он сам называл «теоретической философией» и в меньшей степени исследована «практическая философия». Целый корпус статей социально-философского и политического характера («В защиту демократии», «Какой идеал противопоставить коммунизму?», «Органическое строение общества и демократия», ««Индустриализм, коммунизм и утрата личности» и др.) требует новой оценки наследия Лосского. На протяжении всей жизни русский философ в своих статьях постоянно обращается к проблемам построения правового государства, демократии, значения экономической свободы в обществе, роли науки в государстве. Взгляды Лосского-публициста, общественного деятеля, социального философа, одного из создателей политической доктрины конституционно-демократической партии, не оставившего искания наилучшего пути развития России и после своей вынужденной эмиграции, мало изучены в современной научной литературе. Недостаточно изучено и религиозно-философское мировоззрение Н.О. Лосского, изложенное в работах «Бог и мировое зло», «Христианство и буддизм», «Учение о перевоплощении» и других работах. Исследование и описание архива позволит провести реконструкцию философского наследия Н.О. Лосского и более точно обрисовать контуры его философской системы, выявить ранее незнакомые детали жизни и творчества русского философа. Одной из таких ранее неизвестных страниц жизни Лосско- го стал «контакт» русского философа с Альбертом Эйнштейном [8].

Н.О. Лосский, без сомнения, является одним из самых ярких русских философов $\mathrm{XX}$ в., вклад которого в развитие не только отечественной, но и мировой философии еще недостаточно оценен. Как писал В.В. Зеньковский, «вклад Лосского в русскую философию не только велик и ценен, но в творчестве Лосского русская философия поднялась на высоту, выходящую за пределы русской мысли» $[1$, с. 4].

\section{ПРИМЕЧАНИЕ}

1 Выражаю благодарность руководству Института славянских исследований г. Парижа за предоставленную возможность работы с материалами архива Н.О. Лосского.

\section{СПИСОК ЛИТЕРАТУРЫ}

1. Зеньковский, В. В. Н.О. Лосский / В. В. Зеньковский // Вестник Русского студенческого христианского движения. - 1961. - № 60. - С. 3-4.

2. Левицкий, С. А. Патриарх русской философии (к 90-летию Н.О. Лосского) / С. А. Левицкий // Грани. - 1960. - № 48. - С. 186-193.

3. Ловцкий, Г. Н.О. Лосский. Обоснование интуитивизма. Берлин. Изд. «Обелиск». 1924. / Г. Ловцкий // Современные записки. - Париж, 1924. Кн. XXI (21).- C. 386-391.

4. Лосев, А. Ф. Философия. Мифология. Культура / А. Ф. Лосев. - М. : Политиздат, 1991. -525 с.

5. Лосский, Н. О. Автобиографические материалы, 1935 г. // Архив Н.О. Лосского [неопубликованные материалы]. - Paris : Institut d'études slaves.

6. Лосский, Н. О. Влияния, которым я подвергался // Архив Н.О. Лосского : [неопубликованные материалы]. - Paris : Institut d'études slaves.

7. Лосский, Н. О. Воспоминания: Жизнь и философский путь / Н. О. Лосский. - М. : Викмо Русский путь, 2008. - 400 с.

8. Сердюкова, Е. В. Материалы из архивов Н.О. Лосского и А. Эйнштейна: Дискуссия о пространстве и времени (1950-е гг.) / Е. В. Сердюкова // Вопросы философии. - 2017. - № 1. - С. 81-90.

\section{REFERENCES}

1. Zenkovskiy V.V. N.O. Lossky. Vestnik Russkogo studencheskogo khristianskogo dvizheniya, 1961, no. 60 , pp. 3-4. 
E.B. Сердюкова. Учение Н.О. Лосского как синтез русской и европейской традиций мысли

2. Levitskiy S.A. Patriarkh russkoy filosofii (k 90-letiyu N.O. Losskogo) [The Patriarch of Russian Philosophy (to the $90^{\text {th }}$ Anniversary of N.O. Lossky)]. Grani, 1960, no. 48, pp. 186-193.

3. Lovtskiy G. N.O. Lossky. Obosnovaniye intuitivizma [N.O. Lossky. Justification of Intuitionism]. Sovremennyye zapiski, 1924, no. XXI (21), pp. 386-391.

4. Losev A.F. Filosofiya. Mifologiya. Kultura [Philosophy. Mythology. Culture]. Moscow, Politizdat Publ., 1991. 525 p.

5. Lossky N.O. Avtobiograficheskie materialy [Autobiographical Materials]. Arkhiv N.O. Losskogo (neopublikovannye materialy) [Archive of Nicholas Lossky (Unpublished Materials)]. Paris, Institut d'études slaves, 1935.
6. Lossky N.O. Vliyaniya, kotorym ya podvergalsya [Influences to Which I Was Subjected]. Arkhiv N.O. Losskogo (neopublikovannye materialy) [Archive of Nicholas Lossky (Unpublished Materials)]. Paris, Institut d'études slaves.

7. Lossky N.O. Vospominaniya: Zhizn $i$ filosofskiy put [Memories: Life and the Philosophical Path]. Moscow, Viksmo - Russkiy put Publ., 2008. $400 \mathrm{p}$.

8. Serdyukova E.V. Materialy iz arkhivov N.O. Losskogo i A. Eynshteyna: Diskussiya o prostranstve i vremeni (1950-e gg.) [Materials from the Archives of N.O. Lossky and A. Einstein: a Discussion on Space and Time (the 1950s)]. Voprosy filosofii, 2017, no. 1, pp. 81-90.

\section{Information about the Author}

Elena V. Serdyukova, Candidate of Philosophical Sciences, Associate Professor, Institute of Philosophy and Social-Political Sciences, Southern Federal University, Bolshaya Sadovaya St., 105/42, 344016 Rostov-on-Don, Russian Federation, evserdyukova@sfedu.ru.

\section{Информация об авторе}

Елена Владимировна Сердюкова, кандидат философских наук, доцент, Институт философии и социально-политических наук, Южный федеральный университет, ул. Б. Садовая, 105/42, 344016 г. Ростов-на-Дону, Российская Федерация, evserdyukova@sfedu.ru. 